\title{
One Year of Surface-Based Temperature Inversions at Dome C, Antarctica
}

\author{
Ilaria Pietroni · Stefania Argentini · Igor Petenko
}

Received: 31 July 2012 / Accepted: 12 August 2013 / Published online: 4 October 2013

(C) The Author(s) 2013. This article is published with open access at Springerlink.com

\begin{abstract}
In 2005 the Study of Stable Boundary Layer Environment at Dome C (STABLEDC) experimental campaign was conducted at the plateau station of Concordia at Dome $\mathrm{C}$, Antarctica. Temperature profiles measured with a microwave radiometer were used to study the characteristics of surface-based temperature inversions over the course of a year. Statistics of temperature profiles for every month are discussed; the difference between daytime and nocturnal cases observed during the summer months disappears during winter. Surface-based temperature inversions occurred in $70 \%$ of the time during summer, and almost all of the time during winter. During winter the occurrence of warming events leads to a decrease in the temperature difference between the top and the base of the inversion (i.e. the inversion strength). The inversion strength maxima ranged between $3{ }^{\circ} \mathrm{C}$ (December) and $35^{\circ} \mathrm{C}$ (August) corresponding to gradients of 0.1 and $0.3^{\circ} \mathrm{C} \mathrm{m}^{-1}$, respectively. The average surface-based inversion height presents a daily cycle during the summer months with values up to $200 \mathrm{~m}$ in the morning hours, while it affects a layer always deeper than $100 \mathrm{~m}$ during the winter months. The relationships between inversion strength and the downward longwave radiative flux, absolute temperature, and wind speed are examined. The inversion strength decreases as the longwave radiation increases. A clear anti-correlation between inversion strength and near-surface temperature is evident throughout the year. During the winter, the largest inversion strength values were observed under low wind-speed conditions; in contrast, a clear dependence was not found during the summer.
\end{abstract}

Keywords Antarctic plateau - Microwave radiometer - Temperature inversion . Temperature profiles

I. Pietroni $(\varangle) \cdot$ S. Argentini · I. Petenko Institute of Atmospheric Sciences and Climate, ISAC-CNR, Via del Fosso del Cavaliere 100, 00133 Rome, Italy

e-mail: ilaria.pietroni@artov.isac.cnr.it

I. Petenko

A.M. Obukhov Institute of Atmospheric Physics RAS,

Pyzhevskiy, 3, 119017 Moscow, Russia 


\section{Introduction}

The surface-based temperature inversion (hereafter SBTI) is the most characteristic feature of the atmospheric boundary layer (hereafter ABL) in polar regions. During the night and in winter the formation of the SBTI is common due to the imbalance between the outgoing longwave radiation and the downwelling solar and infrared radiation. The advection of warm air over a cooler surface can occur at any time and can also lead to the development of the SBTI, but this situation is rare in polar regions. Over the Antarctic plateau during the winter the imbalance between surface and atmosphere longwave emission produces a condition of permanent inversion ensuring the presence of a long-lived stable boundary layer. During the summer, in contrast, the formation of a convective layer was observed in the warmest hours of the day (Mastrantonio et al. 1999; Argentini et al. 2005; King et al. 2006; Pietroni et al. 2012), while the SBTI develops during the hours of minimum irradiation. The presence of a permanent condition of the SBTI over the Antarctic plateau leads to important meteorological consequences. The most important of these is the formation of strong katabatic winds observed in the confluence zone along the east Antarctic coast. The katabatic winds are caused by the pool of cold air masses that form in the dome-shaped Antarctic interior and, in the presence of the Coriolis force, air-flows towards the coast (Ball 1956). These winds have a determinant impact in the production and distribution of sea-ice around the continent, and strongly influence the atmospheric circulation in the Southern Hemisphere (Connolley 1996). The knowledge of SBTI behaviour through the year is therefore fundamental in understanding the mechanisms determining the formation and the persistence of the katabatic flow. The importance of accurate models for the stable boundary layer in the polar region has been pointed out by Bromwich et al. (2001) and Cassano et al. (2001). In particular, an incorrect simulation of the stable boundary layer in regional models during the winter over the Antarctic plateau can lead to simulations that fail to fully demonstrate the link between the climate of this region and the global system (Gallée and Gorodetskaya 2010). Studying the performance of the Antarctic Mesoscale Prediction System (described by Powers et al. 2003) in retrieving surface temperature, Bromwich et al. (2005) have shown that over the Antarctic plateau this model gives a positive bias of about $1{ }^{\circ} \mathrm{C}$ during the summer. Lascaux et al. (2009), when comparing 47 radiosoundings temperature profiles collected at Dome $\mathrm{C}$ in the winter of 2005 with the results of a mesoscale model simulation, found substantial differences between experimental and model profiles in the first $200 \mathrm{~m}$ above the surface. Gallée and Gorodetskaya (2010) validated a limited area model over Dome C during the cold season. Comparing the model temperature profiles with the radiosoundings, they found the highest bias (of about $5^{\circ} \mathrm{C}$ ) in the first $100 \mathrm{hPa}$. Too cold values were found near the surface, while too warm values were found in the layers above, implying that the SBTI is not well represented. They stress the importance of a correct simulation of temperature and humidity vertical profiles in representing the warm and cold regimes at Dome $\mathrm{C}$ for an accurate estimate of the longwave radiative fluxes.

Due to the extreme temperatures, dryness and elevation, the Antarctic plateau is considered to be an excellent potential site for conducting astronomical observations that would otherwise only be possible from space. For this reason, in recent years, the optical turbulence over the Antarctic plateau has been the subject of studies by astronomers (e.g. Aristidi et al. 2005a,b; Geissler and Masciadri 2006; Hagelin et al. 2008; Trinquet et al. 2008; Lascaux et al. 2009). As shown by e.g. Marks et al. (1996, 1999) the level of optical turbulence depends on the vertical gradient of the wind velocity and on the SBTI.

The characteristics of the SBTI are also important in the retrieval of temperature profiles from satellite measurements (Liu and Key 2003). Waddington and Morse (1994) and Van 
Lipzig et al. (2002) have pointed to the importance of considering the SBTI for a proper understanding of the paleoclimate from ice cores (Helsen et al. 2005).

Meteorological studies of the SBTI in Antarctica have been done in recent decades in order to characterize the different regions of the Antarctic continent, and primarily to highlight the differences between the coastal and continental regions. Phillpot and Zillman (1970) used radiosoundings from 21 stations (three of which were in the interior) to study the climatology of the SBTI across the Antarctic continent. They found that at the South Pole the SBTI characterized a 500-700 m thick layer and had a strength (i.e. the difference between the temperature at the inversion top and at the ground) of $20^{\circ} \mathrm{C}$ on average during the winter, while over the highest parts of the inner plateau the strength reached on average $25^{\circ} \mathrm{C}$. Using radiosoundings from 15 stations (two of which were in the interior) and data from the UK Meteorological Office Global Climate Model, Connolley (1996) provided an overview of the modelled SBTI over Antarctica. Based on Jouzel and Merlivat (1984), he derived a relationship between surface temperature and the inversion strength over the entire Antarctic continent and noted that the parameters of this relationship depend on terrain slope. However, these results are limited due to the scarce number of observations over the interior of Antarctica. Hudson and Brandt (2005) studied the SBTI at two sites in the interior of Antarctica, and focused on measurements from radiosondes and towers collected over a 10 -year period at the South Pole and measurements collected during two summer periods at Dome C. They described the SBTI throughout the year at the South Pole and the lapse conditions found at Dome C during the summer. The SBTI is related to wind speed as shown by Dalrymple et al. (1966) and Lettau and Schwerdtfeger (1967). Hudson and Brandt (2005) found that in the inner part of the Antarctic plateau the relationship between the SBTI and the wind speed is characterized by the presence of two maxima in the median of the inversion strength: the first occurs at very low wind speeds, the second for wind speeds between 3 and $5 \mathrm{~m} \mathrm{~s}^{1}$. The second maximum is probably due to development of an inversion wind (Schwerdtfeger and Mahrt 1968).

Different instruments are generally used to measure the SBTI and its characteristic parameters. Instrumented towers have the advantage of gathering accurate measurements but have a limited vertical range (a few tens of metres). Over the Antarctic plateau, studies of the SBTI using instrumented towers were conducted at the South Pole by Dalrymple et al. (1966) and Hudson and Brandt (2005), at Plateau Station by Riordan (1977) and Kuhn et al. (1977), and at Dome C by Genthon et al. (2010).

The number of radiosounding campaigns in Antarctica has increased in the last few decades (Schwerdtfeger 1970, 1984; Phillpot and Zillman 1970; Aristidi et al. 2005a; Walden et al. 2005; Turner et al. 2006; Hagelin et al. 2008; Rowe et al. 2008; Seidel et al. 2010; Zhang et al. 2011), albeit radiosoundings have serious limitations due to their high operational cost. For manned stations, such soundings are able to cover either a few hours of the day or the entire day for limited periods during intensive campaigns. A further problem is that radiosoundings cannot give accurate values at the lowest heights, especially when an intense SBTI occurs, and the required corrections in near surface-layer measurements are not obvious (Mahesh et al. 1997).

The use of surface-based passive microwave radiometers for the retrieval of the temperature profiles has strongly increased in recent years. This instrument has a good resolution both in time and space and has the advantage of being unmanned (Kadygrov and Pick 1998).

This paper aims to characterize the SBTI behaviour over the course of 1 year using measurements obtained from a microwave radiometer set at the French-Italian Station of Concordia, at Dome C. The paper is divided into three parts: the experimental site and the measurements are described in Sect. 2, the behaviour of temperature profiles and the 
(a)

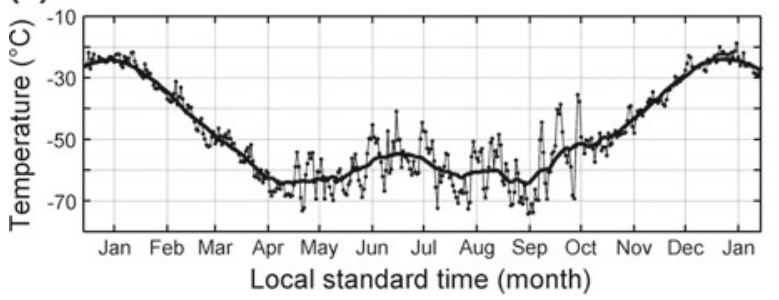

(b)

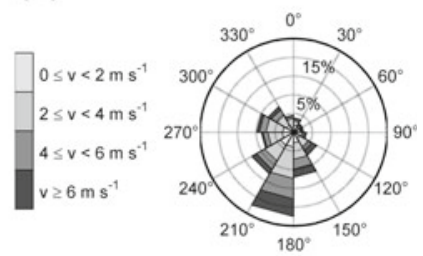

Fig. 1 Behaviour of temperature and wind during STABLEDC: a annual behaviour of the daily-averaged temperature (dotted line) with the running average (full line) superimposed; b wind rose obtained for 12 angular sectors, the winds speeds are divided into $2 \mathrm{~m} \mathrm{~s}^{-1}$ bins from 0 to $6 \mathrm{~m} \mathrm{~s}^{-1}$ and represented in a grey scale

characteristics of SBTI are reported in Sect. 3, and a summary and conclusions are given in Sect. 4.

\section{Site and Instrumentation}

\subsection{Geographical Setting}

The French-Italian Station of Concordia $\left(74^{\circ} 06^{\prime} \mathrm{S}, 123^{\circ} 20^{\prime} \mathrm{E}, 3,233 \mathrm{~m}\right.$ a.s.1.) is located on the Antarctic plateau in the eastern sector of the continent. Dome $\mathrm{C}$, the dome at which the base is located, has an average slope of less than $0.1 \%$. With an unobstructed horizon and negligible advection, the phenomena observed at this site can be considered representative of a large area around the station. A detailed description of this site can be found in Argentini and Pietroni (2010).

In order to characterize the site and to ensure the representativeness of the period under investigation, a brief overview of the mean meteorological parameters (temperature and wind speed) measured by automatic weather stations (AWS) is given below. The daily mean temperature behaviour is shown as a dotted line in Fig. 1a; the full black line represents the running average over a 1-month period centred on each day. The dataset can be divided into seasons according to the shape of the temperature curve (Schwerdtfeger 1970): summer $=15$ November to 31 January; autumn $=1$ February to 31 March; winter $=1$ April to 14 September and spring $=15$ September to 14 November. The summer is characterized by daily mean temperatures ranging from -40 to $-20^{\circ} \mathrm{C}$, by a clear trend before and after the peak value observed at the beginning of January and by low inter-daily variability. During the winter, due to the coupled effect of the absence of solar radiation and the isolation of the plateau from the maritime air masses, a rapid loss of heat occurs in the dry polar-continental atmosphere so that almost constant air temperatures are recorded and the seasonal trend disappears. This behaviour, which is a typical feature of the Antarctic plateau, inspired the well-known term "coreless winter" commonly used in the literature (e. g. Schwerdtfeger 1977). The inter-daily variability during the winter is due to the occurrence of warming events (Astapenko 1964), periods that are characterized by a fast temperature increase of several ${ }^{\circ} \mathrm{C}$ and generally have a duration ranging from 4 to 7 days and a periodicity of about 10 to 15 days (Argentini et al. 2001; Petenko et al. 2007). This phenomenon was observed at various locations in Antarctica and reported previously, but there is still a lack of understanding of its origins and mechanisms of development. Possible mechanisms to explain the warming events include: 
Table 1 Warming events during the winter 2005

\begin{tabular}{lccccc}
\hline April & May & June & July & August & September \\
\hline 2 & $1-4$ & $1-5$ & $1-7$ & $1-5$ & $8-11$ \\
$24-28$ & $20-23$ & $10-11$ & $15-18$ & $9-16$ & \\
& $30-31$ & $14-18$ & $25-26$ & & \\
& & 30 & $30-31$ & & \\
\hline
\end{tabular}

(1) advection of warm and moist air with different air temperature (Carroll 1982; Neff 1999);

(2) vertical mixing of air from different layers (Carroll 1982); (3) variation in longwave radiation emitted by clouds associated with moist air from the upper part of the atmosphere (Schwerdtfeger and Weller 1977; Stone et al. 1990; Stone and Kahl 1991; Stone 1993); (4) nuclei of condensation originating from the coast that reach the interior of Antarctica, producing a variety of types of clouds (Othake 1978). More recently, Petenko et al. (2007) showed that the warming events have different characteristics in different zones of Antarctica depending on site latitude, elevation and proximity to the sea. In particular, at Dome C, the warming episodes are more often associated with high-pressure anomalies accompanied by an increase in wind speed, with flow mainly from the sector north-west to north-east. In the same study, the authors hypothesized that the warming events are due to the passage of cloudy warm air masses advected from the sea when the large-scale pressure anomalies over east Antarctica favour their intrusion into the inner parts of the continent. The warming events observed during the winter of 2005 represent $37 \%$ of the total period and are listed in Table 1.

The statistical analysis of the wind speed and direction is shown in Fig. 1b. In the polar histogram the wind directions are divided into $30^{\circ}$ bins, whereas the wind speed is categorized into four classes: $0-2 \mathrm{~m} \mathrm{~s}^{-1} ; 2-4 \mathrm{~m} \mathrm{~s}^{-1} ; 4-6 \mathrm{~m} \mathrm{~s}^{-1}$ and $>6 \mathrm{~m} \mathrm{~s}^{-1}$ represented on a grey scale. The airflow is from the sector $150-300^{\circ}$ for $75 \%$ of the time, and the strongest winds are from this sector. A seasonal variability has been observed with highest wind speeds observed during the winter (not shown). During the summer, a daily cycle in wind speed occurs (King et al. 2006) with the highest values observed during the day (Zhou et al. 2009).

The behaviour described can be considered representative of the general situation at this site. In fact, the distribution and the annual mean values of the relevant meteorological parameters (namely temperature, wind speed, wind direction and air pressure) collected by AWS during 2005 reveal a substantial agreement with both those collected during the period between 2002 and 2011 and with values reported in Allison et al. (1993) and in Van Lipzig et al. (2004).

\subsection{Instrumentation and Quality Assessment of Temperature Profiles}

During 2005 an experimental campaign was conducted at Concordia Station in the framework of the Study of Stable Boundary Layer Environment at Dome C (STABLEDC) project. The experimental area, flat and clear, was located upwind from the base, at a distance of $1,000 \mathrm{~m}$ in the southern direction. This location ensured that the measurements would not be disturbed by the presence of the buildings. The measurements were taken over the period from 20 December 2004 to 10 January 2006. The aim of the experimental campaign and a complete list of the operational instrumentation during STABLEDC are summarized in Argentini and Pietroni (2010). Here we give only a brief description of the instrumentation relevant to the parameters analyzed below, i.e. temperature profiles, near-surface radiation components, air temperature and wind velocity. 
The ABL temperature profiles were provided by the improved polar version of the Meteorological Temperature Profiler (hereafter MTP 5-P), i.e. a scanning microwave radiometer (Kadygrov and Pick 1998) specifically designed to provide continuous, unattended observations under extreme meteorological polar conditions. The instrument, a single channel microwave radiometer operating in the molecular oxygen absorption band (Kadygrov et al. 1998, 2001), measures the brightness temperature at different discrete elevation angles. The temperature profile is retrieved using the algorithm described in (Kadygrov and Pick 1998), with the boundary conditions given by an external thermometer. A detailed description of the retrieval method used specifically for the MTP 5-P can be found in Argentini et al. (2004). The MTP 5-P allows for the collection of temperature profiles having a high spatial and temporal resolution. In fact the vertical nominal resolution is $10 \mathrm{~m}$ in the first $50 \mathrm{~m}$ of the ABL, and $50 \mathrm{~m}$ up to $600 \mathrm{~m}$ (Kadygrov et al. 2001, 2012); the averaging period is $10 \mathrm{~min}$. During STABLEDC the instrument was mounted on a $5-\mathrm{m}$ tall box, so that the first measurement point is at $5 \mathrm{~m}$.

Although this kind of instrument was only developed in the last few years, it has already been used in different experimental fields due to its transportability, dimensions and high performance. Temperature profiles obtained with a radiometer of the same type, but with a smaller antenna (MTP 5-HE), during a field experiment held in Payerne, were presented by Kadygrov et al. (2005). They investigated the ability of the MTP 5-HE to detect temperature inversions. Comparing the radiometer and radiosonde profiles, they found that the mean difference and root-mean-square are smaller under the inversion conditions than during adiabatic cases. The maximum accuracy that can be achieved is $0.5-0.8^{\circ} \mathrm{C}$. Yushkov and Kouznetsova (2008) compared the nocturnal inversion characteristics obtained with an MTP 5 and a sodar for different land uses (urban and rural areas). According to their measurements, the sensitivity for the MTP 5 was larger at the lower levels (between 200 and $300 \mathrm{~m}$ ). Berger et al. (2006) and Argentini et al. (2009) showed that, in general, this type of radiometer has difficulties in detecting and measuring elevated temperature inversions.

Radiosonde profiles, gathered in the framework of the Routine Meteorological Observations programme (i.e. the basic meteorological measurements collected by the Italian National Antarctic Research Programme for general purposes and meteorological assistance to operations in Antarctica as described in www.climantartide.it), were used to assess the quality of the MTP 5-P measurements. However, these measurements have only been taken since April 2005 and with a frequency of once or twice a week. The temperature sensor mounted in the Vaisala RS 92 sondes is an F-Thermocup (Jauhiainen et al. 2005), which has been described by Luers (1997). The most important source of errors in these sensors is the solar heating (Tomasi 2006). Considering the elevation angle at Dome $\mathrm{C}$, and the fact that only data gathered during the winter were considered, a correction for solar heating is not necessary. As shown by Rowe et al. (2008), a lag correction in the temperature profiles is not necessary for this kind of sonde.

A mast installed near the MTP 5-P was equipped with a four-component radiometer: CNR1 by Kipp \& Zonen, mounted at $2 \mathrm{~m}$ above the snow surface, having a time averaging of $10 \mathrm{~min}$. This instrument combines two CM3 pyranometers for downward and upward broadband shortwave radiation flux (spectral range 305-2,800 nm) and two CG3 pyrgeometers for downward and upward broadband longwave radiation flux (spectral range $5-50 \mu \mathrm{m})$.

Air temperature, wind speed and direction measurements are provided by the AWS Milos 520 by Vaisala with an acquisition rate of $10 \mathrm{~min}$ at a height of $3 \mathrm{~m}$ above the surface. These data are provided by the Antarctic Meteorological Research Center in Wisconsin (ftp://amrc. 

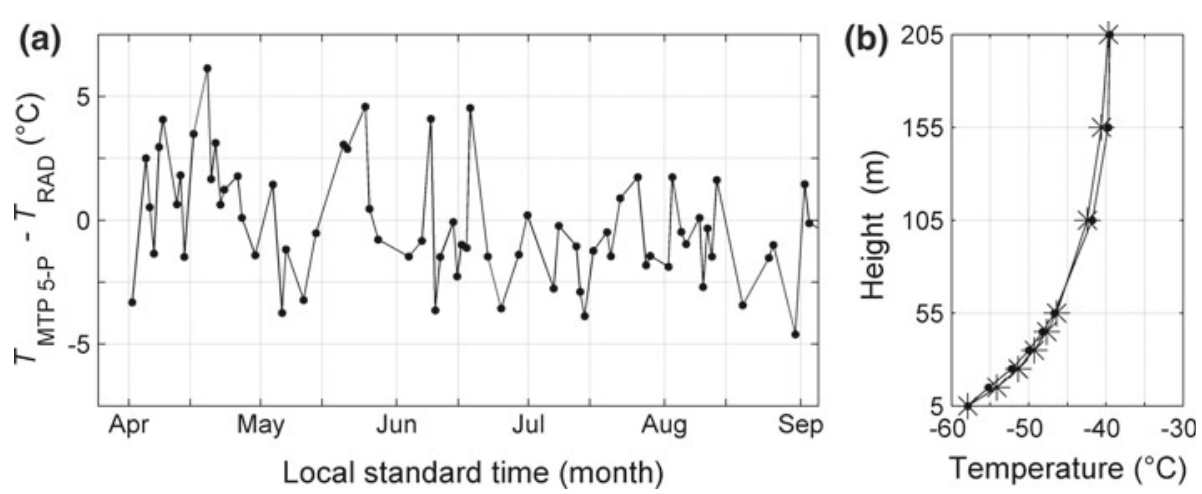

Fig. 2 Comparison between MTP 5-P and radiosounding temperature profiles: a time series of mean difference over the first 205 m; b MTP 5-P (dotted line) and radiosounding (starred line) mean temperature profiles

ssec.wisc.edu). For the entire dataset, any missing data were filled by linear interpolation if the lack of data had a duration $<1 \mathrm{~h}$.

To check the reliability of the microwave radiometer measurements a comparison with radiosounding temperature profiles was conducted, and each pair of profiles (MTP 5-P and radiosounding) has been analyzed independently. The MTP 5-P profiles show a disagreement with the radiosoundings in the upper part of the profiles so that we limit our analysis to the lower $200 \mathrm{~m}$ layer. Figure $2 \mathrm{a}$ shows the time series of the mean differences between the MTP 5-P and radiosounding profiles in the first $205 \mathrm{~m}$ in the period 1 April 2005 to 2 September 2005. The differences range between -3 and $6{ }^{\circ} \mathrm{C}$. These discrepancies can be partially explained by the fact that the MTP 5-P temperature is representative of a layer of at least $10 \mathrm{~m}$ depth, so that the profile is smoother than that obtained with radiosoundings. The day-by-day differences can be attributed to case-to-case changes in the performance of the radiosoundings; probably due to both manufacturing and ventilation differences as shown by Mahesh et al. (1997). These results are in agreement with those of Leuski and Westwater (2001) for the mid-latitude version of the radiometer. The mean temperature profiles taken by the MTP 5-P and the radiosoundings during the period under investigation are represented in Fig. $2 \mathrm{~b}$ as dotted and starred lines respectively, an underestimation of the MTP 5-P up to $1{ }^{\circ} \mathrm{C}$ being found in the first $50 \mathrm{~m}$. This difference can be attributed to the scarce capability of the sondes to adjust to the external temperature before launch (Hudson et al. 2004). These values are comparable both with the differences found in the literature between the MTP 5 and radiosoundings (e.g. Kadygrov et al. 2001; Yushkov and Kouznetsova 2008), and between radiosoundings and tower measurements described by Genthon et al. (2010). In contrast an overestimation of about $0.5^{\circ} \mathrm{C}$ occurs in the layer between 55 and $205 \mathrm{~m}$ (Fig. 2b).

\section{Results}

The temperature behaviour in the low troposphere (below $205 \mathrm{~m}$ ) presents a strong interseasonal variability due to the occurrence of continuous sunlight (summer) or darkness (winter). During the summer months a variation in the temperature profile occurs due to the daily cycle (Hudson and Brandt 2005): a clear SBTI is present at night due to the radiative cooling in the atmosphere. In contrast, during the middle part of the day the temperature decreases with height, and a shallow mixing layer forms (Mastrantonio et al. 1999; Argentini 


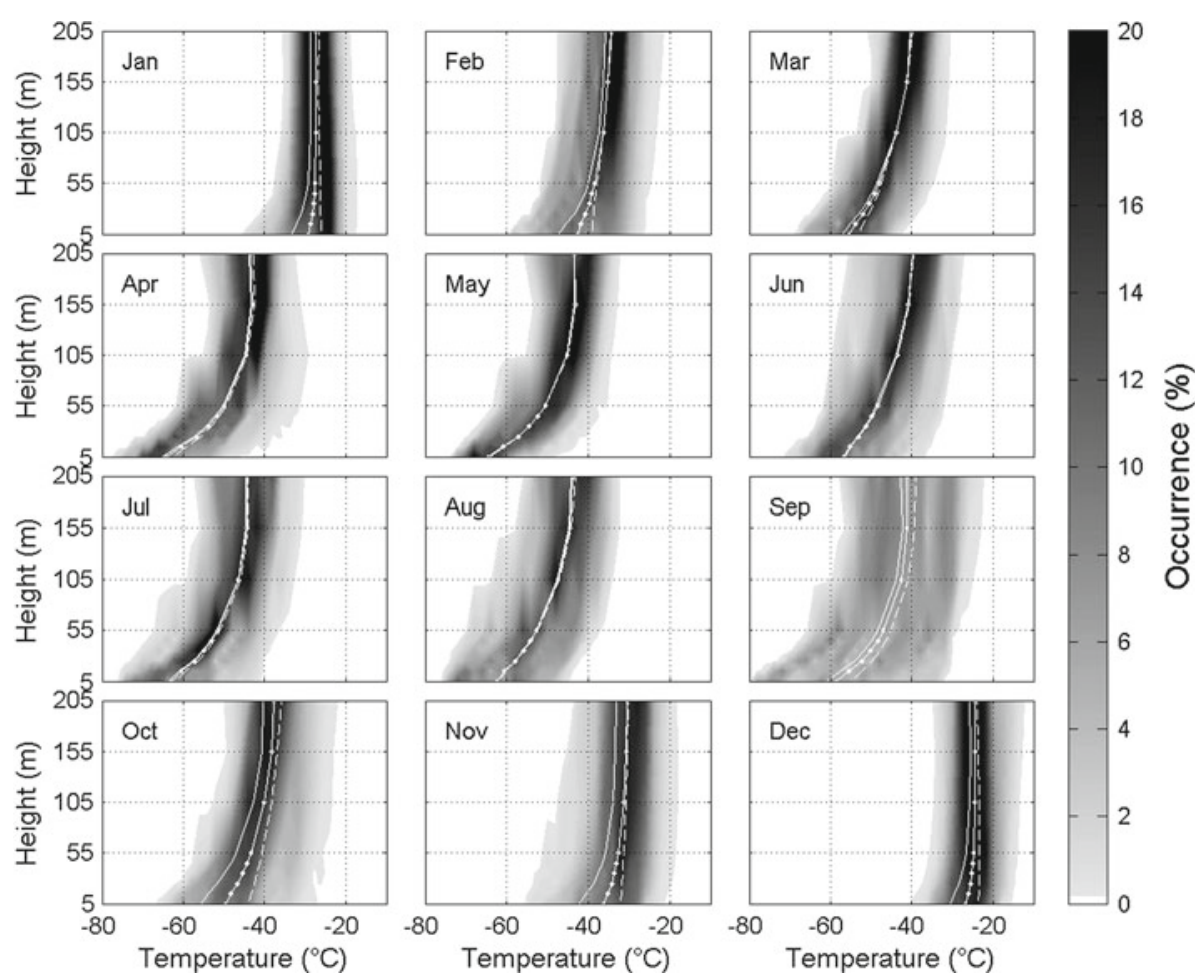

Fig. 3 Monthly distribution of temperature profiles from January 2005 (upper left panel) to December 2005 (lower right panel). The grey scale represents the occurrence of each temperature values at a given height. The white superimposed lines represent the mean temperature profiles during the day marked by a dotted line, during the daytime hours (1000-1400 LST) marked by a dashed line and during the nocturnal hours (2200-0200 LST) marked by full line

et al. 2005). During the winter the daily cycle disappears, and the lower troposphere is in a condition of permanent stability. As a consequence, a strong and persistent SBTI develops.

The large dataset collected during STABLEDC enabled the accurate investigation of the behaviour of temperature profiles during the year. In order to highlight the inter-monthly differences the analysis of the SBTI characteristics has been performed on a monthly basis. Finally, the dependence of the SBTI on the near-surface energy balance (hereafter SEB), temperature, and wind speed is described.

\subsection{Average Temperature Profiles During 2005}

The statistical distributions of the MTP 5-P temperature profiles between 5 and $205 \mathrm{~m}$ for each month are shown in Fig. 3; the grey scale corresponds to the percentage of the temperature values at a given height. The superimposed dotted white lines represent the averaged temperature profiles in the selected period. To highlight the variation during the course of the day the daytime and nocturnal mean profiles averaged in the time intervals 1000-1400 LST (local standard time) and 2200-0200 LST are presented with white dashed and solid lines, respectively.

A rapid process of warming with height generally occurs during the entire year although a considerable difference is observed month by month. During the months of January and 
December the mean profiles are stable in the first few tens of metres, topped by a nearisothermal layer. The probability distribution shows a negative skewness in the first $40 \mathrm{~m}$ and kurtosis increasing with height, indicating that the amplitude of the diurnal cycle is not constant along the vertical, but decreases with height. The daytime profiles are characterized by lapse conditions; in contrast the nocturnal profiles demonstrate the occurrence of the SBTI. During the months of February and November the mean profiles show an SBTI deepening, but lapse conditions are still present during the daytime hours. The kurtosis is small over the entire profile in the months of January and December because these months are characterized by a fast cooling process involving the air masses above the surface (as shown by the nearsurface temperature in Fig. 1a). In October the low SBTI values in the daytime temperature profile associated with the positive skewness indicate a continuous and rapid warming in the 200-m thick layer above the surface. During the coldest months, i.e. from April to September, the SBTI intensifies and involves a thicker layer. In regard to the strength and persistence of the winter SBTI, it is worth noting the similar behaviour during the months of April, May, July and August. June is characterized by an increase in temperature along the vertical and a weakening in the SBTI. This anomaly with respect to the other winter months is probably due to the occurrence of intense warming events (Fig. 1a; Table 1). The month of September is characterized by low kurtosis along the entire profile, implying that the high variability observed at the surface (Fig. 1a) affects also the above layers. During the winter months, the probability distribution in the layers close to the snow surface is positively skewed because the surface can be easily warmed, e.g. by the presence of clouds, while the process of radiative cooling is weak and requires long periods of clear sky. These months are also characterized by the coincidence between daytime and nocturnal profiles due to the complete absence of solar radiation.

\subsection{Analysis of the Surface-Based Temperature Inversions}

The SBTI layer is determined according to its characteristics: height, strength, and gradient. Various definitions of the SBTI height (hereafter $h_{\mathrm{SBTI}}$ ) can be found in the literature, so that a comparison with previous studies may be difficult. Kahl (1990) defines the $h_{\mathrm{SBTI}}$ as the bottom of the first layer in which the temperature decreases with altitude. Thin non-inversion layers are ignored if they are embedded within a deeper inversion layer. The inversion strength (hereafter $\Delta T$ ) is defined as the temperature difference between the top and the base of the inversion. It is worth noting that the level of the inversion base is fixed at ground level, while the top is computed for each profile. The inversion gradient (hereafter $\Gamma$ ) is the ratio between $\Delta T$ and $h_{\text {SBTI }}$. The temperature profiles were interpolated in order to have values at constant intervals of $10 \mathrm{~m}$; as the analysis is performed on profiles ranging between 5 and $205 \mathrm{~m}$, values of $h_{\text {SBTI }}$ above $205 \mathrm{~m}$ could not be determined.

Figure 4 shows the annual temperature behaviour as a function of height (ordinate on the left side). The two lines superimposed represent $h_{\text {SBTI }}$ (black dots, ordinate on the left side) and $\Delta T$ (white line, ordinate on the right side), respectively. Each panel refers to 3 months. The summer months are characterized by a daily cycle in the entire profile reflecting that observed at the surface, but with minor amplitude (Fig. 4a, d). During the winter the temperature changes have the order of the day (Fig. 4b, c). The presence of the winter warming events is evidenced by the light blue or green in the lowest levels topped by a warmer layer (red colour). The $h_{\mathrm{SBTI}}$ values present a well-defined annual trend with values ranging between 5 and $105 \mathrm{~m}$ during the summer months (Fig. 4a, d) and above $105 \mathrm{~m}$ in the remaining periods (Fig. $4 \mathrm{~b}, \mathrm{c}$ ). The $h_{\mathrm{SBTI}}$ values have a diurnal behaviour in the month of 


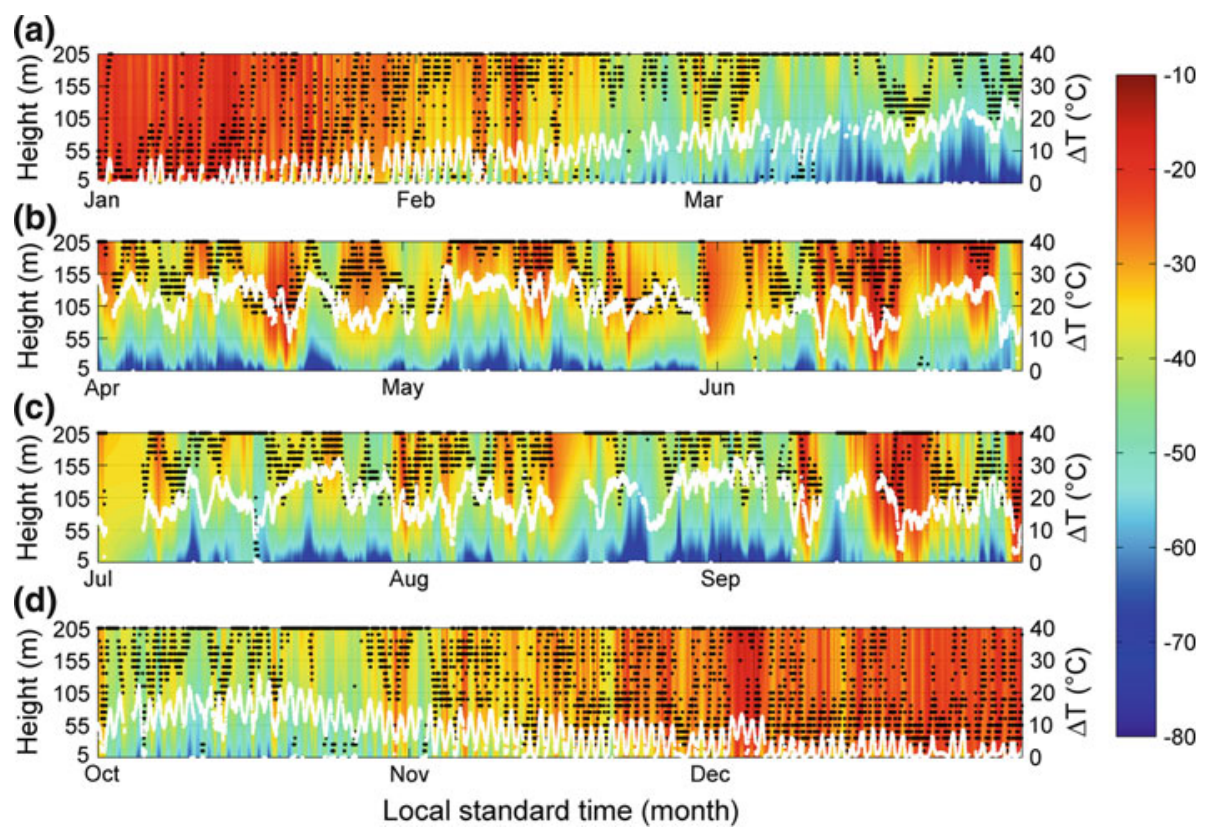

Fig. 4 Temperature profiles (colour scale) in the lowest $205 \mathrm{~m}$ during 2005: a January, February and March; b April, May, June; c July, August, September; d October, November, December. The black dots represents $h_{\mathrm{SBTI}}$ and refers to the left scale of the ordinate; the white line is the $\Delta T$ and refers to the right scale of the ordinate

January and in the first days of February (Fig. 4a), as the SBTI involves a narrow layer during the evening and deepens during the night. With the decrease of the sun elevation the SBTI persists during the whole day, and $h_{\mathrm{SBTI}}$ is characterized by large values. This behaviour persists over the winter months (Figs. 4b, c) until the middle of November (Fig. 4d) when a daily cycle begins again. A similar behaviour is detectable in the time series of $\Delta T$. The annual cycle is evident with the maximum values oscillating between 5 and $30^{\circ} \mathrm{C}$ during the summer (Fig. 4a, d) and winter (Fig. 4b, c), respectively. In the first months of the year (Fig. 4a) $\Delta T$ shows a diurnal cycle that vanishes during the month of February and reappears in the month of October, lasting until December (Fig. 4d). During these months $\Delta T$ ranges between 0 and $15^{\circ} \mathrm{C}$. The values found for the SBTI parameters during the summer are in agreement with those observed at Dome C by Genthon et al. (2010). Hudson and Brandt (2005) studied the SBTI at Dome C during January 2005 using tower measurements, and considering two specified levels $(2$ and $30 \mathrm{~m}$ ) to compute $\Delta T$ they found a maximum value of $6^{\circ} \mathrm{C}$ at $0100 \mathrm{LST}$ that is in agreement with the values presented in Fig. 4 and reported in Table 2. During the period between April and September (Fig. 4b, c) $\Delta T$ oscillates around $20^{\circ} \mathrm{C}$. The variability observed during the winter months must be attributed to the presence of the warming events.

To investigate the influence of these episodes on the SBTI, the averaged temperature profiles for the entire winter, during the warming events only and during the days without warming events, are shown in Fig. 5a as the full dotted line, open circle line and starred line, respectively. The type of profile does not change substantially, although the temperature increases at all levels during the warming events and $\Delta T$ decreases. Figure $5 \mathrm{~b}$ shows the histogram of $\Delta T$ during the winter (black bars) with superimposed values observed during 


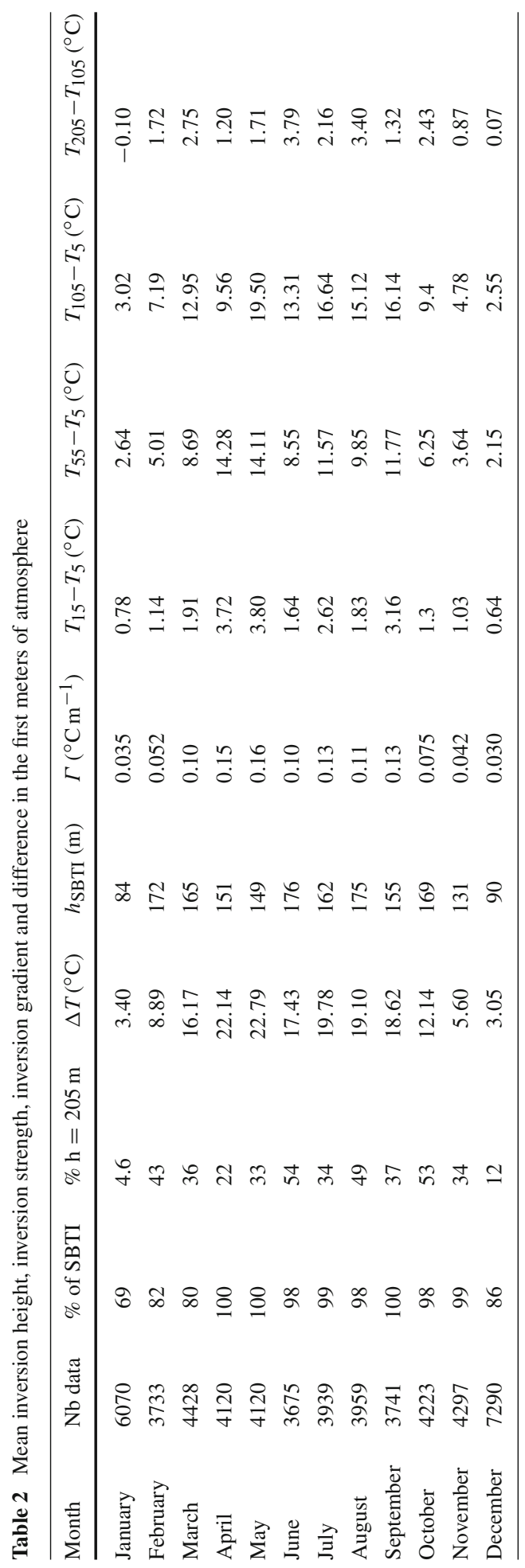



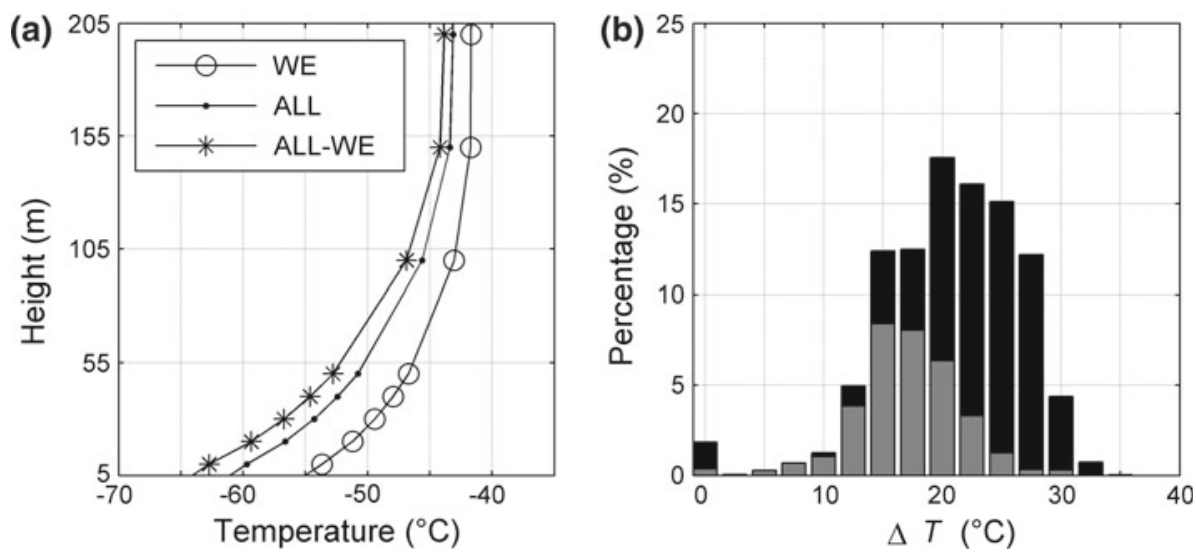

Fig. 5 Effect of warming events in the winter profiles: the open dotted lines represent the mean obtained considering only the warming events, the full dotted line represents the averaged value, and the starred line is the mean obtained disregarding the profiles during the warming events (a). Effect of warming events in the winter distribution of $\Delta T$ : the black bars represent the entire winter, the grey bars the warming events cases (b)

the periods of warming events (grey bars); both the histograms are normalized to the entire winter. The $\Delta T$ distribution during the winter peaks at $20^{\circ} \mathrm{C}$, and the most populated bins are between 22 and $28^{\circ} \mathrm{C}$. During the warming events the $\Delta T$ peak is centred at $15^{\circ} \mathrm{C}$. The values corresponding to the warming events represent the entire winter distribution below $10^{\circ} \mathrm{C}$ and most of the distribution up to $18^{\circ} \mathrm{C}$, confirming a mean decrease in $\Delta T$ of about $5{ }^{\circ} \mathrm{C}$ during the warming events.

The time series of $\Gamma$ during the year depicted in Fig. 6 reveals the presence of an annual trend. During the summer (January, February, November, December) $\Gamma$ is characterized by values $<0.1^{\circ} \mathrm{C} \mathrm{m}^{-1}$ and by a diurnal cycle (Fig. 6a, d). This behaviour is in agreement with that shown for the month of January by Genthon et al. (2010). During the other months $\Gamma$ oscillates around $0.2^{\circ} \mathrm{Cm}^{-1}$ (Fig. $6 \mathrm{~b}, \mathrm{c}$ ); the lowest values (around $0.15^{\circ} \mathrm{Cm}^{-1}$ ) are observed in June. These values are consistent with the potential temperature gradient in the lowest 150 m estimated by Hagelin et al. (2008) using the ECMWF model. Table 2 reports the average values of the parameters describing the SBTI: the first column gives the period under investigation. From the second to the last column the following parameters are given: number of profiles collected during the period, percentage of profiles characterized by a SBTI, percentage of $h_{\mathrm{SBTI}}$ values equal to $205 \mathrm{~m}, h_{\mathrm{SBTI}}, \Delta T, \Gamma$, and temperature difference in layers of 10, 50 and $100 \mathrm{~m}$ depth, respectively, above the reference level of $5 \mathrm{~m}$. The last column reports the temperature difference in the layer 105-205 m. As the field experiment commenced in December 2004 and finished in January 2006, the mean for the months of January and December include the measurements for 2 years. The SBTI occurs in the $69 \%$ of the cases during January and $86 \%$ on December: $h_{\mathrm{SBTI}}<90 \mathrm{~m}$ and $\Delta T \approx 3{ }^{\circ} \mathrm{C}$. The duration of the SBTI increases in February and covers the entire day during the winter months. The $\Delta T$ for this period presents mean values oscillating around $20^{\circ} \mathrm{C}$. For all the year, especially for the months of January and December, these values are larger than those found at the South Pole by Hudson and Brandt (2005).

As shown by the time series reported in Figs. 4 and 6, a clear diurnal cycle in the SBTI characteristics is observable during the summer, while it is absent during the winter months. In order to detail this cycle, the diurnal behaviour of the occurrence of $h_{\mathrm{SBTI}}, \Delta T$, and $\Gamma$ for 2 months, namely January and July, representative of summer and winter, respectively, 

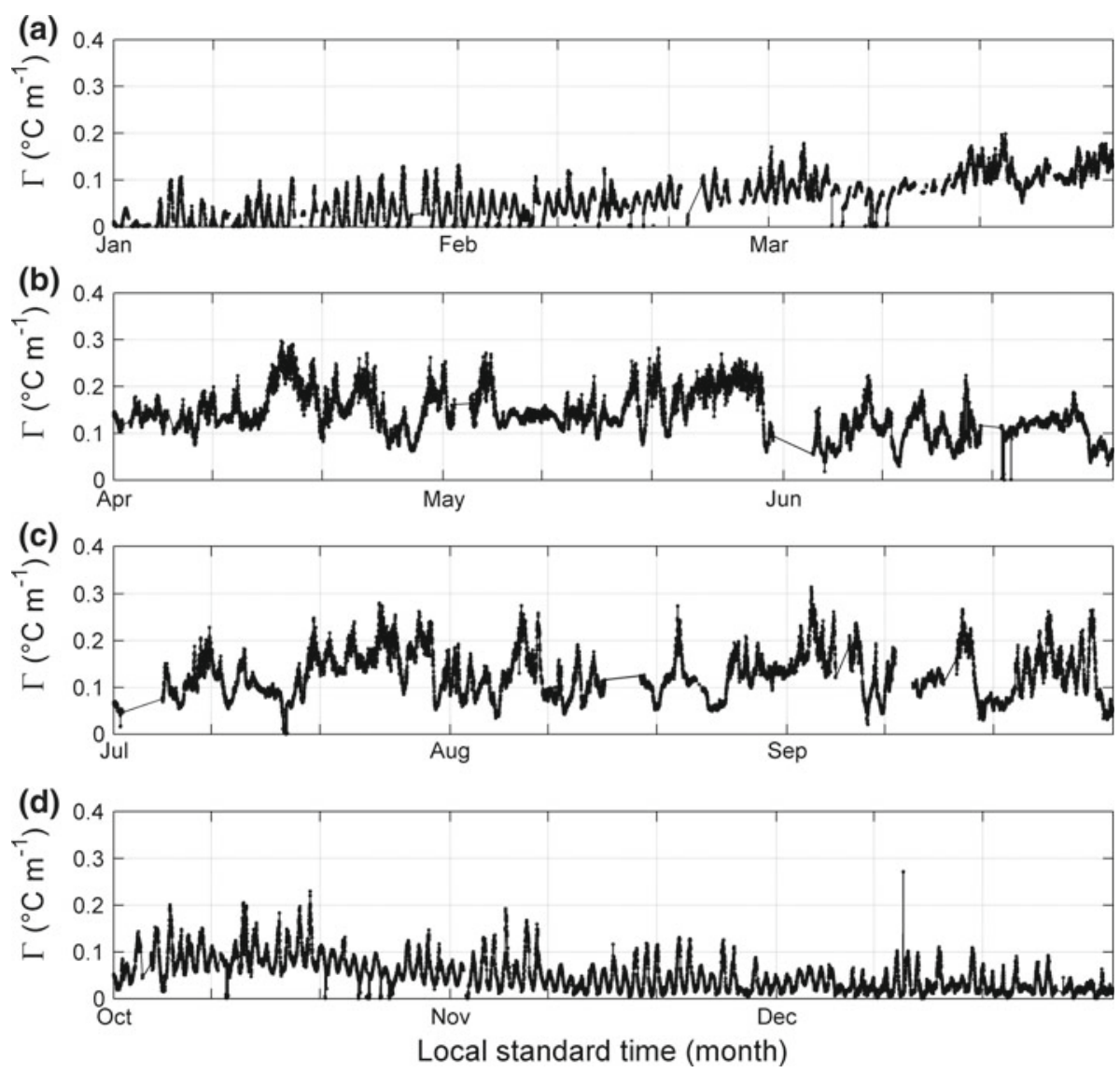

Fig. 6 Behaviour of $\Gamma$ the during 2005: a January, February and March; b April, May, June; c July, August, September; d October, November, December

is reported in Fig. 7. In January the SBTI is almost absent between 0900 and 1500 LST (Fig. 7a, c, e). The $h_{\text {SBTI }}$ varies between 0 and $205 \mathrm{~m}$ with the most probable values in the layer below $105 \mathrm{~m}$ (Fig. 7a). The observed daily cycle in $h_{\mathrm{SBTI}}$ is in agreement with that shown by Aristidi et al. (2005b) who studied the temperature profiles at Dome $\mathrm{C}$ for 2 days during the summer 2003-2004. In July, the $h_{\text {SBTI }}$ ranges between 75 and $205 \mathrm{~m}$ (Fig. 7b): the higher occurrence is observed at the top of the range, while a uniform distribution is observed below. An analogous behaviour characterizes $\Delta T$, which presents a pronounced daily cycle in January (Fig. 7c) ranging between $0{ }^{\circ} \mathrm{C}$ (reached around midday) and $13{ }^{\circ} \mathrm{C}$ (reached at 0200 LST). The $\Delta T$ values are uniformly distributed in a broader range between 10 and $30^{\circ} \mathrm{C}$ during the month of July (Fig. $7 \mathrm{~d}$ ). $\Gamma$ ranges between 0 and $0.15^{\circ} \mathrm{C} \mathrm{m}^{-1}$ during the night in January (Fig. 7e) and between 0.07 and $0.22^{\circ} \mathrm{C} \mathrm{m}^{-1}$ in July (Fig. 7f).

\subsection{Influence of Near-Surface Parameters on SBTI}

Over the Antarctic plateau the surface radiative cooling is the primary process influencing the SBTI. Other relevant parameters are the surface temperature and the wind speed. We here report the dependence of SBTI on these parameters. The SEB equation can be written as 

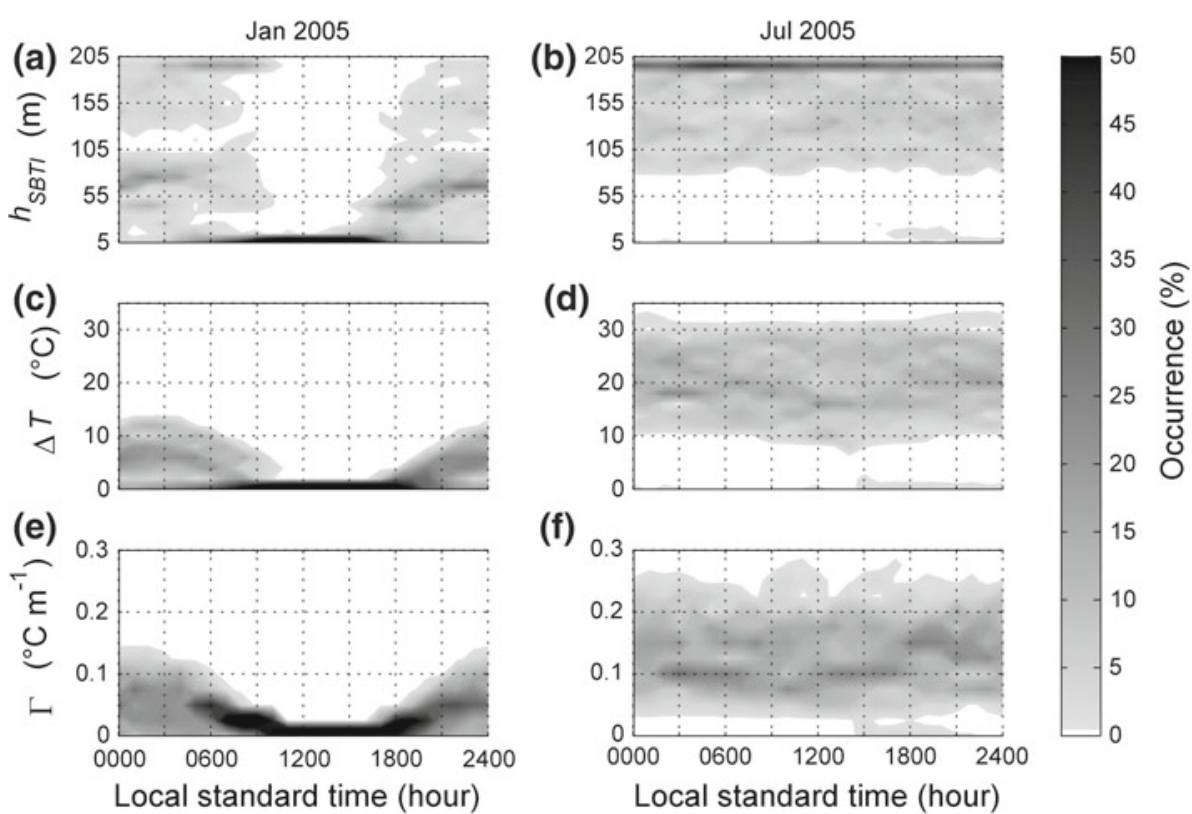

Fig. 7 Daily behaviour of $h_{\mathrm{SBTI}}, \Delta T$, and $\Gamma$ for the month of January, representative of summer, and July, representative of winter

$$
H_{0}+L_{\mathrm{E}}+L W_{\downarrow}+L W_{\uparrow}+S W_{\downarrow}+S W_{\uparrow}-G=0
$$

where $H_{0}$ is the sensible heat flux, $L_{\mathrm{E}}$ is the latent heat flux, $L W_{\downarrow}$ and $L W_{\uparrow}$ denote incoming and outgoing longwave radiative fluxes, respectively, $S W_{\downarrow}$ and $S W_{\uparrow}$ denote incoming and outgoing shortwave radiative fluxes, respectively, and $G$ is the ground heat flux. Sublimation, evaporation from liquid and melting are included in $L_{\mathrm{E}}$. All components refer to the airsnow interface and are defined positive toward the snow surface. The sensible heat flux is derived from eddy-covariance measurements using a sonic thermo-anemometer (Metek USA1) installed at $3.6 \mathrm{~m}$, sampling at $10 \mathrm{~Hz}$. Unfortunately, this instrument functioned properly only at temperatures above $-60{ }^{\circ} \mathrm{C}$, so that during the winter only a few measurements, mainly those related to the warming events, are available. For this limitation we cannot fully investigate the dependence of SBTI on $H_{0}$. The second term of the equation, namely $L_{\mathrm{E}}$, is usually omitted in the Antarctic SEB as its value is negligible respect to the others, and its relative uncertainty would be high due to the difficulties in measurement. For the calculation of $G$ we use the measurements of three thermometers deployed at $0.05,0.15$, and $0.30 \mathrm{~m}$ below the snow surface and a HFP01 flux plate at $0.10 \mathrm{~m}$. The dependence of the SBTI parameters on $G$ is not shown because it is not clear, especially during the winter. The surface radiation budget is extremely low over the Antarctic plateau because during winter little or no shortwave radiation is present, so that the primary role is played by the longwave radiation. During the summer, the surface heating due to the absorption of shortwave radiation introduces a diurnal cycle (Georgiadis et al. 2002) and, despite the high surface albedo limits the amount of solar radiation available to heat the surface, the SBTI can be destroyed by convection as seen in the previous paragraph. For these reasons the following analysis is limited to the longwave radiation. In order to highlight the role of cloudiness $L W_{\downarrow}$ is considered. The impact of the longwave radiation on the SBTI is shown in Fig. 8. The increase in $L W_{\downarrow}$ under overcast 

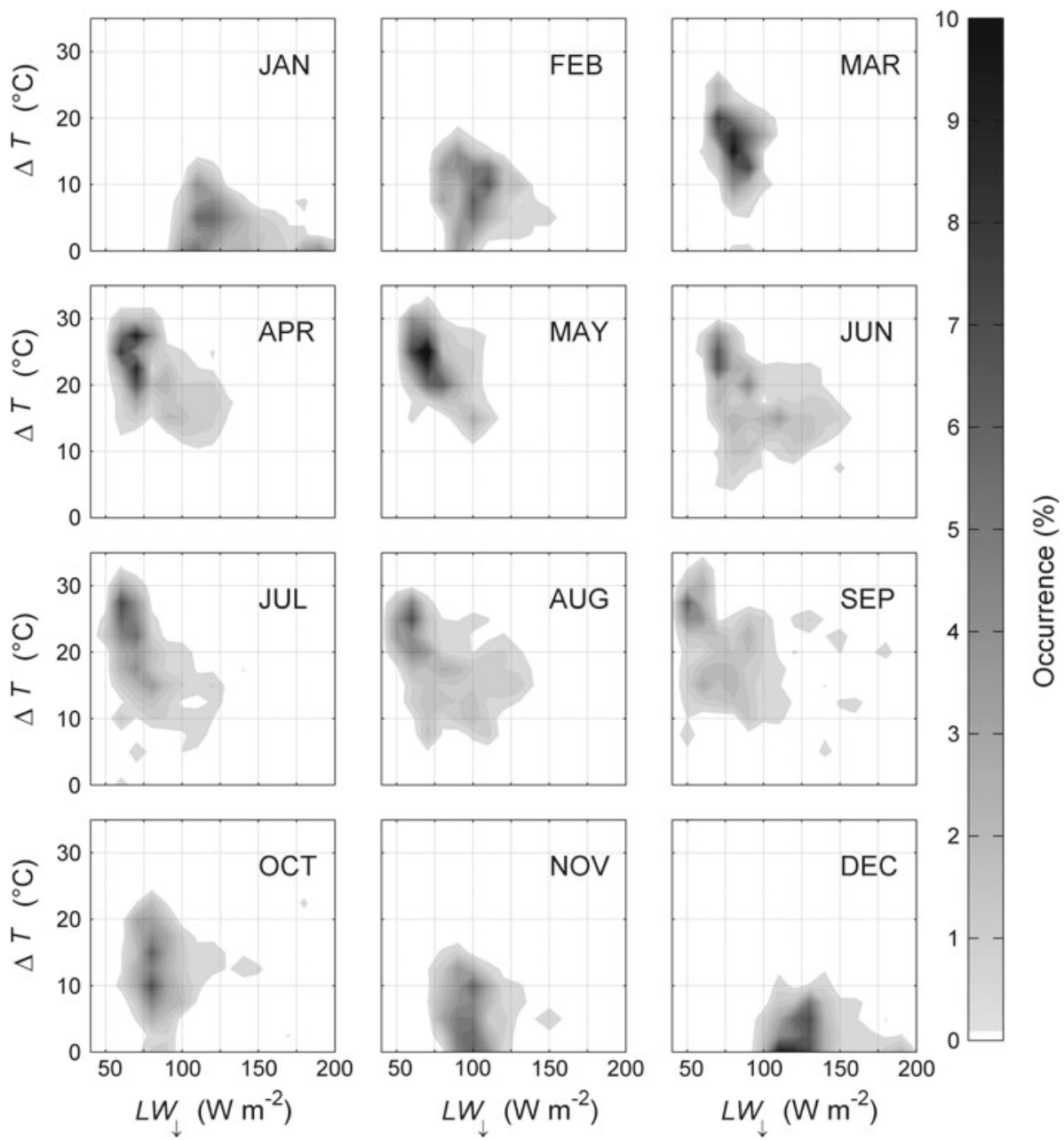

3

$-$

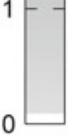

Fig. 8 Dependence between $\Delta T$ and $L W_{\downarrow}$ during the months of 2005. The grey scale represents the occurrence for each month

conditions is expected to produce a warming of the surface, or at least reduce its cooling rate, thus reducing $\Delta T$. As shown in Fig. $8 \Delta T$ tends to decrease when $L W_{\downarrow}$ increases. During the winter months for $L W_{\downarrow}<75 \mathrm{~W} \mathrm{~m}^{-2}$ the $\Delta T$ distribution reaches a plateau with values varying within a wide range. This behaviour indicates that below this threshold value the radiative cooling is no longer the dominant process. This behaviour confirms the findings of Hudson and Brandt (2005) who demonstrate the existence at the South Pole of a plateau in the median value of $\Delta T$ for values of $L W_{\downarrow}<80 \mathrm{~W} \mathrm{~m}^{-2}$. The behaviour observed in June (and with minor intensity in August) seems to be due to the combined effect of cloudiness and high wind speed. In fact, during this month, a general increase in $L W_{\downarrow}$ linked to the cloudiness is evident. Values of $L W_{\downarrow}>120 \mathrm{~W} \mathrm{~m}^{-2}$ are associated with flow from the sector north-east to northnorth-west advecting warm and moist air from the coast. In these situations $\Delta T$ decreases, ranging from 10 to $20^{\circ} \mathrm{C}$. For southerly flow the value of $L W_{\downarrow}$ decreases dramatically; if strong winds occur the radiative cooling is not the dominant process and $\Delta T$ reduces as 

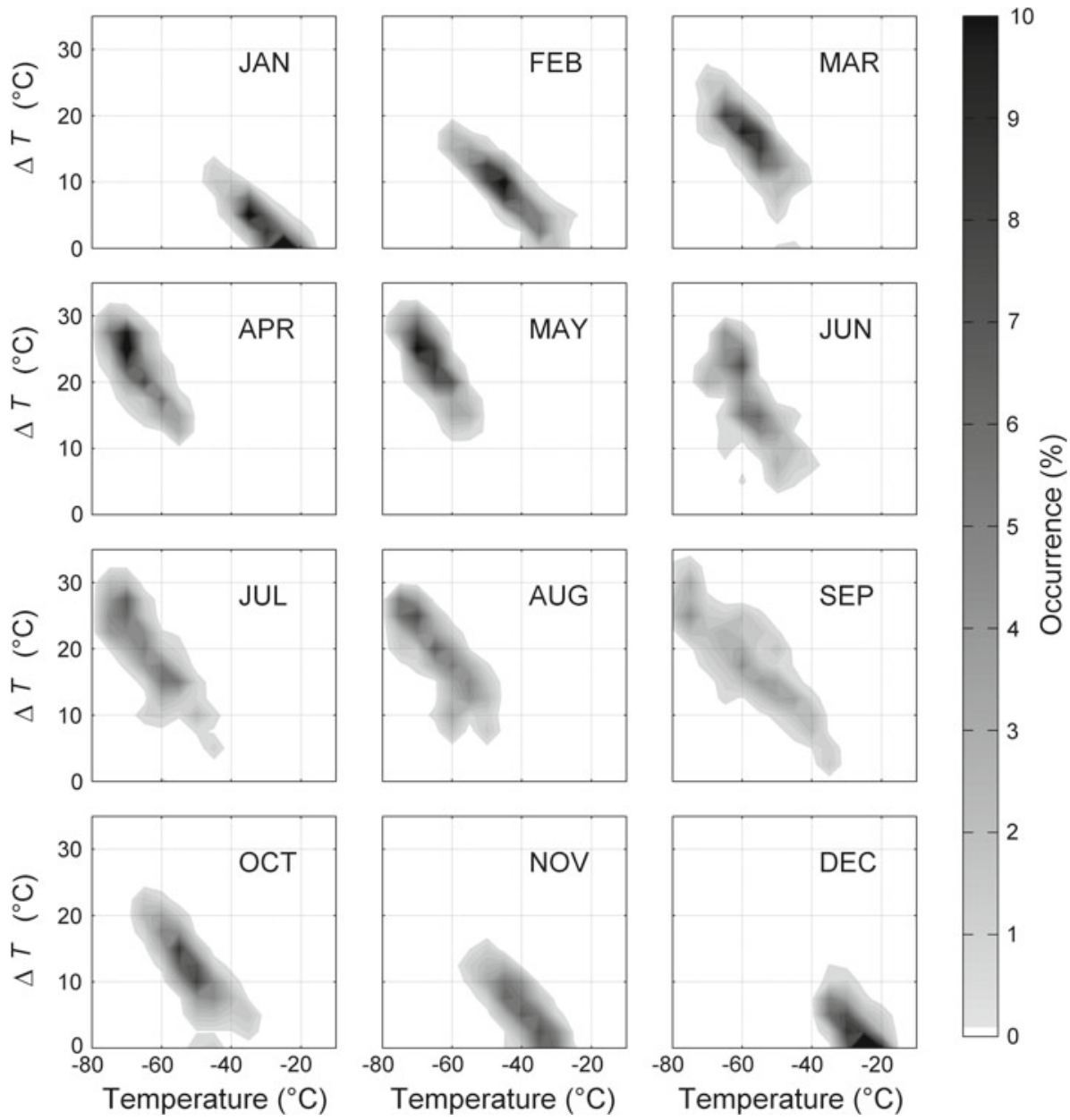

Fig. 9 Dependence between $\Delta T$ and near-surface temperature during the months of 2005. The grey scale represents the occurrence for each month

a consequence of the vertical mixing. In contrast, the maximum in $\Delta T$ is associated with low wind conditions. An analogous behaviour is shown by $L W_{\uparrow}$ (not shown). During the months of January, February, November and December the behaviour is less clear. In fact, in these months the presence of solar radiation plays the main role in the surface energy balance.

The correlation between $\Delta T$ and surface temperature is well documented in the literature, in particular at high latitudes (e.g. Bradley et al. 1992; King et al. 2003). Analyzing measurements from various places in Antarctica Connolley (1996) proposed a relationship between $\Delta T$ and surface temperature, and showed a dependence of the relationship coefficient on slope terrain. The dependence of $\Delta T$ on near-surface temperature is shown for each month in Fig. 9. The grey scale represents the occurrence of a given $\Delta T$ normalized to the total number of measurements during the month. Due to the diurnal cycle of temperature, a strong anti-correlation $(-0.85)$ between the temperature and $\Delta T$ is present in January, and fluctu- 

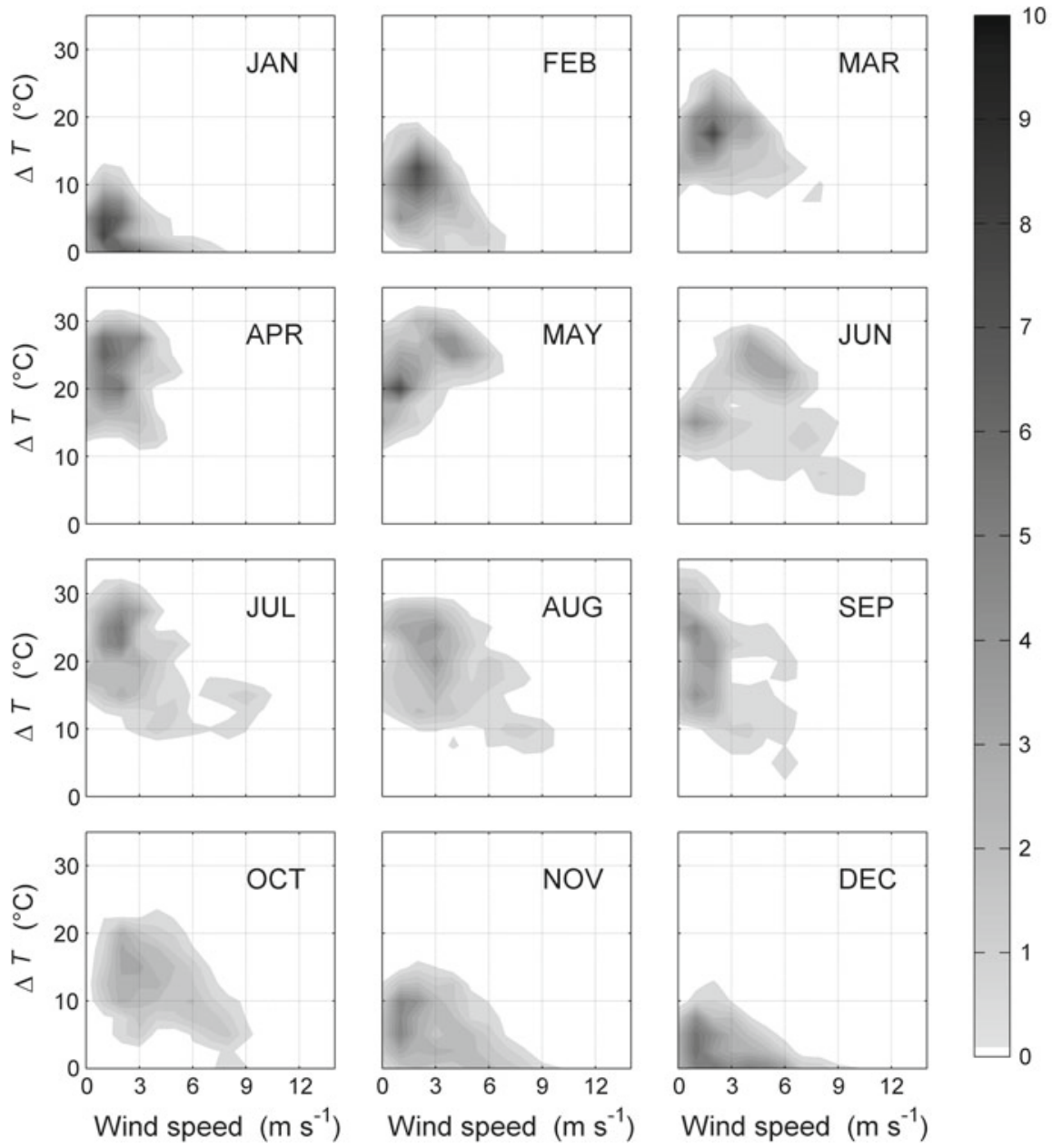

Fig. 10 Dependence between $\Delta T$ and near-surface wind speed during the months of 2005. The grey scale represents the occurrence for each month

ates around -0.7 during other months. The link between temperature and $h_{\mathrm{SBTI}}$ is less clear: during the summer months the higher inversions are observed during period characterized by low temperatures, while during the winter a large scatter in the measurements is found, without any clear relationship between these two parameters (not shown).

Figure 10 shows the dependence of $\Delta T$ on near-surface wind speed. Strong winds lead to increased levels of mechanical turbulence, and colder air close to the surface is mixed with warmer air aloft. As a result of this mixing process, a weakening in the SBTI occurs. Low winds are instead expected to support the development and the maintenance of the SBTI. In January, February, November and December, due to the diurnal cycles of wind speed (King et al. 2006), the values of $\Delta T$ span between 0 and $20^{\circ} \mathrm{C}$ in corresponding to wind speeds $<3 \mathrm{~m} \mathrm{~s}^{-1}$. As the wind speed increases $\Delta T$ tends to decrease; however, as mentioned by Genthon et al. (2010), it is not possible to find a clear relationship between these two quantities. During the other months the highest $\Delta T$ were observed alongside the lowest 
wind velocities. In April and May the presence of weak winds leads to a flat distribution in $\Delta T$. In the month of June $\Delta T$ is lower than in the other months due to the occurrence of wind speeds $>6 \mathrm{~m} \mathrm{~s}^{-1}$. The plateau in the distribution observed during the winter months for wind speeds $<3 \mathrm{~m} \mathrm{~s}^{-1}$ is specific to the Antarctic plateau where the slope is small and flow cannot be created by the presence of SBTI (as observed in other places of Antarctica, e. g. at the South Pole by Hudson and Brandt (2005).

During the winter months the general increase in $h_{\text {SBTI }}$ was found to correspond to the highest wind speed.

\section{Summary and Conclusions}

The measurements collected during the STABLEDC field experiment held at Concordia Station in 2005 are analyzed. The temperature profiles derived with a scanning microwave radiometer were used to determine the surface-based temperature inversion and its behaviour in relation to the main atmospheric parameters. Data analyzed can be considered representative for a large area around the station and for different situations occurring in the East Antarctic plateau. The results obtained were expected, but the time and height resolution in measurements, the vertical extent of the profiles, and the duration of the campaign add detail to previous work.

The SBTI characterizes the entire year, but with different characteristics. In fact the parameters used to describe the SBTI, i.e. $h_{\mathrm{SBTI}}, \Delta T$ and $\Gamma$, show a monthly trend, with slight values in January that increase from February to August, then decrease from October to December.

During the summer months the SBTI occurs $67 \%$ of the time and is interrupted by lapse conditions occurring during daytime. A diurnal cycle characterizes all the SBTI parameters: $h_{\mathrm{SBTI}}$ varying between 5 and $205 \mathrm{~m}, \Delta T$ showing a maximum at $0200 \mathrm{LST}$ and $\Gamma$ ranging between 0 and $0.15^{\circ} \mathrm{Cm}^{-1}$.

During the winter months the surface-based inversion occurs $99 \%$ of the time, and the daily cycle disappears. The observed values of $h_{\mathrm{SBTI}}$ are $>100 \mathrm{~m}$, associated to $\Delta T$ ranging between 10 and $30^{\circ} \mathrm{C}$ and $\Gamma$ that can overpass $0.3{ }^{\circ} \mathrm{C} \mathrm{m}^{-1}$. In these months the only changes observed in the SBTI characteristics are due to the warming events, during which $\Delta T$ decreases significantly.

The analyses of the dependence of $\Delta T$ on the near-surface measurements of $L W_{\downarrow}$, temperature and wind speed show that during the winter months, $\Delta T$ decreases as $L W_{\downarrow}$ increases, with a plateau reached for $L W_{\downarrow}<75 \mathrm{~W} \mathrm{~m}^{-2}$. The $\Delta T$ is anti-correlated with the near-surface temperature. The strongest SBTI occurs in the presence of weak winds when the radiative cooling is the dominant process. Under these conditions the SBTI thickens and its strength increases with time. In contrast, the $\Delta T$ decreases in the presence of high wind speed. The analysis done for the month of June shows the role of the warming events: the warming events are accompanied by an increasing in $L W_{\downarrow}$, coastal wind and a decreasing in $\Delta T$.

Acknowledgments This research was supported by the Italian Antarctic Research Programme (PNRA) in the framework of the French-Italian "Dome C" project. The authors wish to thank the logistics staff at Concordia for their support during the experimental fieldwork and everyone who contributed to the field experiments. The authors thank the RMO staff for providing radiosoundings at Concordia. Special thanks are due to Dr. G. Dargaud who spent the winter 2005 at Concordia station. The authors also wish to thank Dr. G.Mastrantonio, Dr. A. Viola and Mr. A. Conidi for their contributions in the realization of STABLEDC. 
Open Access This article is distributed under the terms of the Creative Commons Attribution License which permits any use, distribution, and reproduction in any medium, provided the original author(s) and the source are credited.

\section{References}

Allison I, Wendler G, Radok U (1993) Climatology of the East Antarctic ice sheet $\left(100^{\circ} \mathrm{E}\right.$ to $\left.140^{\circ} \mathrm{E}\right)$ derived from automatic weather stations. J Geophys Res 98:8815-8823

Argentini S, Pietroni I (2010) An integrated observing system for boundary layer monitoring at Concordia station, Antarctica. In: Cimino N, Marzano F, Visconti V (eds) Integrated ground-based observing systems, vol 2. Springer, Berlin, pp 199-208. doi:10.1007/978-3-642-12968-1_12

Argentini S, Petenko I, Mastrantonio G, Bezverkhnii V, Viola A (2001) Spectral characteristics of East Antarctica meteorological parameters during 1994. J Geophys Res 106:12463-12476

Argentini S, Conidi A, Viola A, Mastrantonio G, Ferrara N, Petenko I, Kadygrov EN, Koldaev AV, Viazankin A (2004) Temperature measurements at Dome C using a new microwave temperature profiler. X workshop on Antarctic atmosphere, Rome

Argentini S, Viola A, Sempreviva A, Petenko I (2005) Summer boundary-layer height at the plateau site of Dome C, Antarctica. Boundary-Layer Meteorol 115:409-422. doi:10.1007/s10546-004-5643-6

Argentini S, Pietroni I, Gariazzo C, Amicarelli A, Mastrantonio G, Pelliccioni A, Petenko I, Viola A (2009) Boundary layer temperature profiles by a RASS and a radiometer: differences, limits and advantages. Nuovo Cimento B 124:549-564

Aristidi E, Agabi A, Fossat E, Azouit M, Martin F, Sadibekova T, Travouillon T, Vernin J, Ziad A (2005a) Site testing in summer at Dome C Antarctica. Astron Astrophys 444(2):651-659

Aristidi E, Agabi A, Azouit M, Fossat E, Vernin J, Travouillon T, Lawrence JS, Meyer C, Storey JWV, Halter B, Roth WL, Walden V (2005b) An analysis of temperatures and wind speeds above Dome C, Antarctica. Astron Astrophys 430(2):739-746

Astapenko PD (1964) Atmospheric process in the high latitudes of the Southern Hemisphere. Israel Program for Scientific Translations, Jerusalem, p 286

Ball FK (1956) The theory of strong katabatic winds. Austr J Phys 9:373-386

Berger H, Ruffieux D, Huguenin P, Calpini B, Roulet Y-A (2006) Validation of ground-based remote sensing temperature profiles with radio-soundings. In: Proceedings of instruments and observing methods, IOM No.94 TECO-2006, WMO technical conference on meteorological and environmental instruments and methods of observation, Geneva, Switzerland, P2(14)

Bradley RS, Keimig FT, Diaz HF (1992) Climatology of surface-based inversions in the north American Arctic. J Geophys Res 97:D1415699-D1415712

Bromwich DH, Cassano JJ, Klein T, Heinemann KM, Hines KM, Steffen K, Box JE (2001) Mesoscale modelling of katabatic winds over Greenland with the polar MM5. Mon Weather Rev 129:2290-2309

Bromwich DH, Monaghan AJ, Manning KW, Powers JG (2005) Real-time forecasting for the antarctic: an evaluation of the Antarctic mesoscale prediction system (AMPS). Mon Weather Rev 133:579-603

Carroll JJ (1982) Long-term means and short-term variability of the surface energy balance components at the South Pole. J Geophys Res 87:4277-4286

Cassano JJ, Box JE, Bromwich DH, Li L, Steffen K (2001) Verification of polar MM5 simulations of Greenland's atmospheric circulation. J Geophys Res 106:13 867-13 890

Connolley WM (1996) The Antarctic temperature inversion. Int J Climatol 16:1333-1342

Dalrymple PC, Lettau HH, Wollaston SH (1966) South Pole micrometeorology program: data analysis. In: Rubin MJ (ed) Studies in Antarctic meteorology. Antarctic research series, vol 9. American Geophysical Union, Washington DC, pp 13-57

Gallée H, Gorodetskaya IV (2010) Validation of a limited area model over Dome C, Antarctic plateau, during winter. Clim Dyn 34:61-72

Geissler K, Masciadri E (2006) Meteorological parameters analysis above Dome C using data from the European centre for medium-range weather forecast. PASP 118:1048-1065

Genthon C, Town MS, Six D, Favier V, Argentini S, Pellegrini A (2010) Meteorological atmospheric boundary layer measurements and ECMWF analyses during summer at Dome C, Antarctica. J Geophys Res 115:D5. doi:10.1029/2009JD012741

Georgiadis T, Argentini S, Mastrantonio G, Viola A, Sozzi R, Nardino M (2002) Boundary layer convectivelike activity at Dome Concordia, Antarctica. Il Nuovo Cimento 25:425-431

Hagelin S, Masciadri E, Lescaux F, Stoesz J (2008) Comparison of the atmosphere above South Pole, Dome C and Dome A: first attempt. Mon Notice Royal Astron Soc 387:1499-1510 
Helsen MM, Van de Wal RSW, Van den Broeke MR, Van As D, Meijer HAJ, Reijmer C (2005) Oxygen isotope variability in snow from western droning maud land, Antarctica and its relation to temperature. Tellus 57B(5):423-425

Hudson SR, Brandt RE (2005) A look at the surface based temperature inversion on the Antarctic plateau. J Clim 18:1673-1696

Hudson SR, Town MS, Walden VP, Warren SG (2004) Temperature, humidity, and pressure response of radiosondes at low temperatures. J Atmos Ocean Technol 21:825-836

Jauhiainen $\mathrm{H}$ et al (2005) Performance of the Vaisala radiosonde RS92-SGP and Vaisala Digicora sounding system MW31 in the WMO Mauritius radiosonde Intercomparison. Vaisala manual, February 2005

Jouzel J, Merlivat L (1984) Deuterium and oxygen 18 in precipitation: modelling of the isotopic effects during snow formation. J Geophys Res 89:11749-11757

Kadygrov EN, Pick DR (1998) The potential for temperature retrieval from an angular-scanning single-channel microwave radiometer and some comparisons with in situ observations. Meteorol Appl 5:393-404

Kadygrov EN, Gaikovich KP, Westwater ER, Han Y, Widener KB (1998) Potential performance of boundary layer temperature profile microwave remote sensing: results of field testing at various latitude zones. In: Proceedings of the 8th atmospheric radiation measurement (ARM) science team meeting, Tucson, Arizona

Kadygrov EN, Kadygrov VE, Lykov AD, Miller EA, Troitsky AV (2001) Investigation of the atmospheric boundary layer thermodynamics on the base of microwave remote sensing. In: Paper presented at 11 th ARM science team proceedings, Atlanta, Georgia

Kadygrov EN, Khaikin M, Miller E, Shaposhnikov A, Troitsky AV (2005) Advanced atmospheric boundary layer temperature profiling with mtp-5he microwave system. In: Proceedings of the WMO technical conference on instruments and methods of observation, Bucharest, Romania, May 2005

Kadygrov EN, Miller EA, Nekrasov VV, Shaposhnikov AN, Troitsky AV (2012) MTP5PE - New instrument for temperature profiling in polar region. In: Proceedings of the 9th international symposium on tropospheric profiling, L'Aquila, Italy, September 2012, ISBN 978-90-815839-4-7

Kahl JD (1990) Characteristics of the low-level temperature inversion along the Alaskan Arctic coast. Int J Climatol 10:537-548

King JC, van Lipzig NPM, Connolley WM, Comiso JC (2003) Are temperature variations at Antarctic ice core sites representative of broad-scale climate variations? In: Proceedings of 7th international conference on polar Meterology, pp 12-16 May, Hyannis, MA, USA

King JC, Argentini S, Anderson PS (2006) Contrasts between the summertime surface energy balance and boundary layer structure at Dome C and Halley stations, Antarctica. J Geophys Res 111:D02105. doi:10. 1029/2005JD006130

Kuhn M, Lettau HH, Riordan AJ (1977) Stability-related wind spiraling in the lowest 32 meters. In: Meteorological studies at Plateau Station, Antarctica. Antarctic Research Series, vol 25. American Geophysical Union, Washington DC, pp 93-111

Lascaux F, Masciadri E, Hagelin S, Stoesz J (2009) Mesoscale optical turbulence simulations at Dome C. Mon Notice Royal Astron Soc 398:1093-1104

Lettau HH, Schwerdtfeger W (1967) Dynamics of the surface-wind regime over the interior of Antarctica. Antarct J U S 2:155-158

Leuski VY, Westwater ER (2001) Measurement of boundary-layer temperature profiles by a scanning 5-MM radiometer during the 1999 winter NSA/AAO radiometer experiment and WVIOP. In: Proceedings of 11th ARM science team meeting, Atlanta, Georgia, pp 1-11

Liu Y, Key J (2003) Detection and analysis of clear sky, low-level atmospheric temperature inversions with MODIS. J Atmos Ocean Technol 20:1727-1737

Luers JK (1997) Temperature error of the vaisala RS90 radiosonde. J Atmos Ocean Technol 14:1520-1532

Mahesh A, Walden VP, Warren SG (1997) Radiosonde temperature measurements in strong inversion: correction for thermal lag based on an experiment at the South Pole. J Atmos Ocean Technol 14:45-53

Marks RD, Vernin J, Azouit M, Briggs JW, Burton MG, Ashley MCB, Manigault JF (1996) Antarctic site testing: microthermal measurements of surface-layer seeing at the South Pole. Astron Astrophys Suppl Ser 118:385-390

Marks RD, Vernin J, Azouit M, Manigault JF, Clevelin C (1999) Measurement of optical seeing on the high Antarctic plateau. Astron Astrophys Suppl Ser 134:161-172

Mastrantonio G, Malvestuto V, Argentini S, Georgiadis T, Viola A (1999) Evidence of a convective boundary layer developing on the Antarctic Plateau during the summer. Meteorol Atmos Phys 71:127-132

Neff WD (1999) Decadal time scale trends and variability in the tropospheric circulation over the South Pole. J Geophys Res 104:27 217-27 251

Othake T (1978) Atmospheric ice crystals at the South Pole in summer. Antarct J U S 13:174-175

Petenko I, Argentini S, Pietroni I, Viola A (2007) Warming events during winter in Antarctica. In: Proceedings of 9th workshop Italian research on Antartic atmosphere, Rome, Italy, pp 119-132 
Phillpot HR, Zillman JW (1970) The surface temperature inversion over the Antarctic continent. J Geophys Res 75:4161-4169

Pietroni I, Argentini S, Petenko I, Sozzi R (2012) Measurements and parametrizations of the atmospheric boundary-layer height at Dome C, Antarctica. Boundary-Layer Meteorol 143:189-206. doi:10.1007/ s10546-011-9675-4

Powers JG, Monaghan AJ, Cayette AM, Bromwich DH, Kuo Y-H, Manning KW (2003) Real-time mesoscale modeling over Antarctica: the Antarctic mesoscale prediction system (AMPS). Bull Am Meteorol Soc $84: 1533-1545$

Riordan AJ (1977) Variations of temperature and air motion in the 0- to 32-meter layer at Plateau Station, Antarctica. In Meteorological Studies at Plateau Station, Antarctica. Antarctica Research Series, vol 25. AGU, Washington DC, pp 113-127. doi:10.1029/AR025p0113

Rowe PM, Miloshevich LM, Turner DD, Walden VP (2008) Dry bias in Vaisala RS90 radiosonde humidity profiles over Antarctica. J Atmos Ocean Technol 25:1529-1541

Schwerdtfeger W (1970) The climate of the Antarctic. In: Orvig S (ed) Climates of the polar regions, vol 14. World Survey of Climatology, Elsevier, pp 253-355

Schwerdtfeger W (1977) Temperature regime of the South Pole: results of 20 years' observations at AmundsenScott Station. Antarct J U S 12:156-159

Schwerdtfeger W (1984) Weather and climate of the Antarctic. Elsevier, Amsterdam, p 261

Schwerdtfeger P, Mahrt LJ (1968) The relation between the Antarctic temperature inversion in the surface layer and its wind regime. In: Proceedings of the international symposium on antarctic glaciological exploration (ISAQE), vol 86. ICSU, SCAR, and IASH, pp 308-315

Schwerdtfeger P, Weller G (1977) Radiative heat transfer processes in snow and ice. In: Businger JA (ed) Meteorological studies at Plateau Station. Antarctic research series, vol 25. American Geophysical Union, Washington DC, pp 35-39

Seidel DJ, Ao CO, Li K (2010) Estimating climatological planetary boundary layer heights from radiosonde observations: comparison of methods and uncertainty analysis. J Geophys Res 115:D16113. doi:10.1029/ 2009JD013680

Stone RS (1993) Properties of austral winter clouds derived from radiometric profiles at the South Pole. J Geophys Res 98:D712961-D712971

Stone RS, Kahl JD (1991) Variations in Boundary layer Properties associated with Clouds and Transient weather disturbance at the South Pole during winter. J Geophys Res 96:D35137-D35144

Stone RS, Dutton GE, DeLuisi JJ (1990) Surface radiation and temperature variations associated with cloudiness at the South Pole. Antarct J Rev 24:230-232

Tomasi C et al (2006) Characterization of the atmospheric temperature and moisture conditions above Dome C (Antarctica) during austral summer and fall months. J Geophys Res 111:D20305. doi:10.1029/ 2005JD006976

Trinquet H, Agabi A, Vernin J, Azouit M, Aristidi E, Fossat E (2008) Nighttime optical turbulence vertical structure above Dome C in Antarctica. Publ Astron Soc Pac 120:203-211

Turner J, Lachlan-Cope TA, Colwell SR, Marshall GJ, Connolley WM (2006) Significant warming of the Antarctic winter troposphere. Science 311:1914-1917

Van Lipzig NPM, Van Meijgaard E, Oerlemans J (2002) The effect of temporal variations in the surface mass balance and temperature-inversion strength on the interpretation of ice-core signals. J Glaciol 48:611-621

Van Lipzig NPM, Turner J, Colwell SR, Van den Broeke MR (2004) The near-surface wind field over the Antarctic continent. Int J Climatol 24:1973-1982

Waddington ED, Morse DL (1994) Spatial variations of local climate at Taylor Dome, Antarctica: implications for paleoclimate from ice cores. Ann Glaciol 20:219-225

Walden P, Town M, Halter B, Storey J (2005) First measurements of the infrared sky brightness at Dome C, Antarctica. Publ Astron Soc Pac 117:300-308

Yushkov VP, Kouznetsova IN (2008) Comparison of nocturnal inversion characteristics obtained by sodar and microwave temperature profiler. In: Paper presented at 14th ISARS-IOP publishing IOP conference series on earth and environmental science, vol 1, pp 012047. doi:10.1088/1755-1307/1/1/012047

Zhang Y, Seidel Dj, Golaz J-C, Deser C, Tomas RA (2011) Climatological characteristics of Arctic and Antarctic surface-based inversions. J Climatol 24:5167-5186

Zhou M, Zhang Z, Zhong S, Lenschow D, Hsu H-M, Sum B, Gao Z, Li S, Bian X, Yu L (2009) Observations of near-surface wind and temperature structures and their variation with topography and latitude in East Antarctica. J Geophys Res 114:D17115. doi:10.1029/2008JD011611 